\title{
How to Prepare Children with Autism to Visit a Dentist?
}

\author{
Karimi M* \\ D.M.D, B.S, Department of Pediatric, Sepideh Dental Clinic, Iran
}

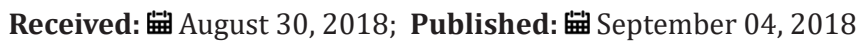

*Corresponding author: Karimi M, D.M.D, B.S, Department of Pediatric, Sepideh Dental Clinic, Iran

\section{Opinion}

One of the most common problems that parents with children with autism have is to take them to a doctor's or dentist's office. Even if the office environment is friendly and the dentist or doctor or their assistants are kind to the child, children who have autism do not like others to come close to them, touch them, and when they are alone, someone is in contact with their bodies. When children's physical environment is invaded, they react to this behavior and do not cooperate with the other person, and sometimes they even become aggressive. It should be said that in many cases, these children are torn apart. There are many problems when a child visits a dentist's office. For example, special smells, a tray of dental instruments, and devices and tools may pose a threat to the peaceful world of these children. For a child with autism spectrum disorder, a dental office is full of insecurity and, consequently, is an unpleasant place [1,2].

\section{Preparation by Parents}

Here are some simple solutions that parents can do to help their children with autism when they plan to go to the dentist's office. Make a medical bag ready for your child; it is best to let him choose this bag by himself. Meanwhile, give him times to get acquainted with the tools inside the bag so that to find out what they are. After spending some time, show him what these tools are used for, and first try them on your own, siblings or someone else. The next step is to run the show with your child, pretending to be a doctor and treat him with these tools. Now ask your child to change his place with you, and let him try this tool on you, his sister or brother or someone else. You can also use a puppet or a stuffed doll or even your own pet to display these tools. Explain to your child what each device is used for, and let him access the toys toolbox and play with them freely. When friends, neighbors, and relatives come to your home, let them play with this gadget with your child, and then tell them to change their role with your child. Remember, if your child can find a playmate to practice with these tools, he will be great of help. If possible, give him a medical phone or more realistic tools to practice with them; however, in this case, you need to make sure your child is monitored and is safe. Give him a prize after each real meeting or show-up meeting with a dentist, or returning from the medical laboratory. Finally, play with your doctor's true name when your child feels comfortable in the "Physician and Patient" game. In addition, along with this medicine toolbox, you can read books about meeting with the dentist too [3].

\section{How to Take an Autistic Child to a Dental Office?}

It can be difficult for every child to visit a dentist, but for a child with autism, referral to the dentist is very scary. Here are some tips for parents that will make this condition easier for their autistic children [4-6].

\section{Before the Appointment}

a. First Method: Try to get an appointment from dental centers that have been established for people with disabilities. These centers experience the treatment of disabled children and usually know what to do to make your child feel relaxed and happy during treatment. If your child needs something special at a specific time, please inform the center before visiting. You can also tell them about your child's interests so that the dental center's staff can talk to him about his interests while he is being treated [7].

b. Second Method: Consider the appointment for a day when your child is not busy. In order to minimize the stress on your child, it is advisable to rest well before going to the dentist. So, consider a day to visit that your child has not done much. This will reduce her stress and cry. In order to provide him with the ideal condition, it is advisable for the dentist to have free time before and after the visit so that he can cope with the situation well [8].

c. Third Method: Try to tell stories about the dentists for your child. Dentists are usually a frightening person for autistic children. So, if they know what happens when they are treated, their fear will be reduced.

d. Fourth Method: Talk to him about the fears your child may face. The mouth is a sensitive part of the body, and for some 
autistic children, this part has a special sensitivity. As a result, your child may have many concerns. Therefore, confirm his emotions and trust him; for example, you can tell him"It's quite common for you to be afraid, so many people are afraid of a dentist. But I know this doctor. He always tries to be very careful and do his work the best. I know you do not want to go to dentistry, but the dental practitioner takes care of your teeth to make sure that they are healthy. We have to go there, but you may not love him. “

e. Fifth Method: Plan for a stimulus activity. For example: watching a movie, visiting his favorite park and even buying a small toy are things that can make your child happy. Before you go to the dentist, choose this activity and be sure it will be very helpful. Try telling your child about this encouraging activity, because he has hope for reaching that. For example: If your child has a lot of interest in the ribbons, tell him: "After dentistry, we go shopping and you can buy two ribbons." As a result, when your child is in fear, he will think about his ribbons during the treatment. If you think that your child will be tired after dentistry, try to consider small activities. Do not use food as encouragement, because after the treatment, he cannot eat for a while.

f. Sixth Method: Give him food before leaving. Your child can not eat anything for a while after dental procedures. A hungry child is a child who easily cries and gets tired. Make sure your child has eaten her food, and then brush her teeth without any hurry [10-12].

\section{When Visiting the Dentist}

a. Method 1: Inform your child that you are ready to go to the dentist. Your child should brush his teeth before leaving the house. Let him bring something like a toy or any other device to the dentist office which makes him more comfortable. Do not hurry him because it can cause stress in your child. Try telling him the plan a few hours before you are leaving. This way, if needed, he can finish doing his work without any anxiety.

b. Method 2: Be extremely patient and kind. If your child is stressful, he will behave strangely because he actually fights emotionally. Be gentle and consider that it will not be easy for your child too. Try to do things in your car that your child is interested in. Play his favorite music, talk with him about your interests; or if he is interested in singing, try to sing a song together. You should know that your child needs to be assured about the condition; may ask you questions repeatedly, so give him a peaceful answer.

c. Method 3: Talk with the dental center staffs, and ask for help for the comfort and relaxation of your child. Perhaps they are able to create a situation in which your child can have a more pleasant visit to the dentist.

d. Method 4: Thinking of not being beside him, may cause this image that you are leaving him which may develop more fear and stress. Make assure your child that you would be in the waiting room if he will need you. If your child is getting disturbed by being away from you, ask the dentist to let you stay in the room with him.

e. Method 5: Encourage and admire her after the meeting. Tell her she has done this job very well, and keep on the encouraging activity you have been considering. This will make him feel better about doing anything. If your child has had bad conditions during the treatment (crying, screaming, etc.), you should tell him: "It's not the courage to not be afraid, the courage is to face it, and you did it very well. Although the dentistry is scary and difficult, you did it ". Tell him you are proud of him [13].

\section{Characteristics of Children with Autism}

These children have certain behavioral characteristics, some of which include:

Impairment of speaking or not speaking at all, and repeating words and sentences spoken by people around him

i. Susceptible to restlessness and discomfort due to problems in the sensory process, anxiety, fears, and difficulty of communicating

ii. Exaggerated reactions to smells, voices, special tastes and other sensory incitements

iii. Excessive use of body movements to calm himself up, such as shaking hands and waving hands

iv. Failure to respond when calling his name so that the child seems to be deaf

v. Express the discomfort of breaking up routines and habits, and reacting to changes

vi. Restlessness and agility, the need to play and touch objects, and anything around

vii. Avoiding eye and physical contact

viii. Problems in social skills

ix. Obsessive-compulsive and adherence to them

$\mathrm{x}$. Lack of effective self-perception of his feelings and others

xi. The difficulty in understanding security and risk aversion.

xii. Performing repetitive games for consecutive hours

Also, these children prefer to play alone and have little fancy imagination. Some may also have symptoms of hyperactivity and early angry [14].

\section{Oral Condition in Children with Autism}

Children with autism often have no differences with normal children in the structures of the teeth, but as these children tend to eat soft and sweet foods, they sometimes have muscle weakness around their mouth. As a result, the reduction in the efficiency of 
the chewing is observed, and even sometimes they tend to keep the mouthfuls long in their mouth, which increases the rate of caries in these children. Also, due to the inability to brush correctly, and the lack of proper cooperation with parents, caries, and gingivitis are more common in these children [15].

\section{Special Considerations for Dental Care in Patients with Autism}

Those with autism need help in understanding and focusing on dental treatment. Often several appointments are required to get acquainted with dentistry and introductory affairs. It is important for the parents of the patient to arrange a friendly visit between the dentist and oral health staff and their children in the first session so that their children get acquainted with the staff and trust them. If the dental team already knows that the patient is suffering from autism disorder, it is recommended that they contact the family of the patient in advance. Collecting information about the patient will be very helpful in a dentist's telephone interview. Furthermore, Obtaining a series of information can be useful, including focusing on patient abilities, child's interests, what rewards are appropriate, whether the child speaks, or if not the best way to communicate, whether the child has fears; or whether he has fears of a particular type like high sound or bright light, and so on.

\section{Differences in Dental Treatment in Children with Autism and Other Children}

Considering the mentioned characteristics, dental treatment is one of the challenges of families with children with autism, because of their inability to properly process the sounds of the devices, the light of dental units and other environmental characteristics; as well as the lack of verbal and ocular communication, and the reduction of concentration and sudden movements of the body makes it difficult for the dentist to treat autistic children [16].

\section{Dental Recommendations for Autistic Patients}

i. It is best to allow the child to remain in the dental office environment during the examination session so that to have a sense of familiarity with the environment.

ii. Talk to the dentist about the special circumstances of the child, especially if he has a history of seizure.

iii. Let the child bring his toy, bed sheet or his favorite dolls to the dentistry.

iv. Since children with autism tend to be more uniform in their affairs, it is better to do their dental work in an appropriate environment by a pediatric dentist. This will increase the chances of improving collaboration at multiple meetings.

v. Dental sessions should be brief, along with encouraging and reinforcing positive behaviors.

vi. The dentist uses certain methods to treat children with autism, including introducing dental instruments and step-bystep treatments. Parenting cooperation with the dentist and following his instructions, and maintaining their relaxation during treatment, will help improve the treatment process.

vii. Due to the possibility of a sudden physical movement of these children, the dentist may ask parents to help hold the child; or may use certain equipment.

\section{Dental Treatments Under General Anesthesia and Sedation}

Autism has different types and severity and symptoms vary from one child to another. Some autistic children are not in any way able to collaborate in dental treatment so that the performing a dental work in a clinic or an office environment may be hazardous to them. Also, the quality of dental work may also change due to the lack of cooperation of the child. So for these children, dental treatments are performed under general anesthesia or sedation. These treatments are performed in a hospital environment and all dental procedures are performed in most cases in one session. In most cases, if the condition is favorable, the patient is not required to be admitted into the ward, and the child is discharged after dental procedures and waking up completely.

\section{Essential Oral Health Measures at Home}

Parents are responsible for providing good oral health. Tooth brushing by him is not a contraindication, but it is not enough. Toothbrush training for a child with autism, like many other things, should be done step-by-step.

To teach how to brush the kid's teeth, time should be allocated for each step. For example, the first step is to open the toothpaste, the second step is to put away the toothpaste's cap, the third step to put toothpaste on the toothbrush, the fourth step is to close the toothpaste's cap, the fifth step is to start brushing on the teeth, and the final stage is rinsing the mouth. These training should be given to the child in a relaxed and pleasant way so brushing is presented as a pleasant work to the child. In severe cases of autism where children have severe resistance, given the importance of oral hygiene, parents should face each other while their knee is in contact, and the child is placed on the parent's lap. One parent keeps the child's legs and hands, and the other parent, while holding the kid's head, will do the tooth brushing technique.

\section{Bruxism in Patients with Autism}

Many affected children squeeze their teeth during the night or even the day, and this may lead to the formation of enamel cracks or the breaking of restorations placed on the teeth. Sometimes certain medicines are prescribed by the physician for autistic children. Many of these medications reduce the flow of saliva and cause dry mouth. Some children with autism often experience gag reflexes, even with minor irritations, which may cause gastric acid to enter the oral cavity and cause erosion of the enamel.

\section{Regular Dental Visits}

According to the special needs of these children, dental examinations should be carried out regularly and within 4-6 
months. Preventive work such as fluoride therapy helps the dentist to prevent the recurrence of caries.

If a child has autism, parents should pay more attention to their child oral health than other peers. Since the failure to establish social connections, learning disabilities and speech impairment are among the most common symptoms of autism, the oral and dental condition of these children needs special attention. In many cases, due to the limited awareness of some families, these children refer to the dentist with inflammation of gum and advanced caries and sometimes untreatable one.

\section{The Possibility of the Diagnosis of Autism from a Child's Tooth}

American researchers say that by analyzing the child's dental layers, it can be determined which children are affected by autistic dysfunction. This study paves the way for the development of a new diagnostic test for autism that can be done at an early stage after birth. The study, conducted by researchers at the University of Mount Sinai, School of Medicine in the United States, suggests that by studying the metabolic pathway of two zinc and copper nutrients in children, it can be predicted who might be exposed to autism. By comparing children with autism with their normal siblings, they found that there were significant differences in the level of copper and zinc in children's teeth.

\section{References}

1. (2013) Centers for Disease Control and Prevention (CDCP). Autism Spectrum Disorders (ASDs) - Facts about ASDs.

2. Paul Curtin PhD, department of environmental medicine and public health, Icahn School of Medicine at Mount Sinai, New York City; Andrew Adesman, M.D., chief, developmental and behavioral pediatrics, Cohen Children's Medical Center, New Hyde Park; Mount Sinai Medicine.

3. (2013) American Psychiatric Association. Diagnostic and statistical manual of mental disorders. ( $5^{\text {th }}$ edn $)$, American Psychiatric Association, Arlington, Virginia.
4. Greenspan, Stanley and Weider, Serena (2006) Engaging Autism. Da Capo Press, USA.

5. National Institute of Dental and Craniofacial Research: Practical Oral Care for People with Autism.

6. Lewis C, Vigo L, Novak L, Klein EJ (2015) Listening to Parents: A Qualitative Look at the Dental and Oral Care Experiences of Children with Autism Spectrum Disorder, Pediatric Dentistry 37(7): E98-E104.

7. Autism Spectrum Disorder (2015) Data and Statistics. Centers for Disease Control and Prevention.

8. McKinney CM, Nelson T, Scott JM (2014) Predictors of unmet dental need in children with autism spectrum disorder: results from a national sample. Acad Pediatr 14(6): 624-631.

9. Loo CY, Graham RM, Hughes CV (2008) The caries experience and behavior of dental patients with autism spectrum disorder. J Am Dent Assoc 139(11): 1518-1524

10. Hernandez P, Ikkanda Z (2011) Applied behavior analysis: behavior management of children with autism Spectrum disorders in dental environments. JADA 142(3): 281-287.

11. American Psychologists Association.

12. Green D, Flanagan D (2008) Understanding the autistic dental patient. Gen Dent 56(2): 167-171.

13. Schaaf RC, Toth Cohen S, Johnson SL, Outten G, Benevides TW (2011) The everyday routines of families of children with autism examining the impact of sensory processing difficulties on the family. Autism 15(3): 373-389.

14. Delli K, Reichart PA, Bornstein MM, Livas C (2013) Management of children with autism spectrum disorder in the dental setting: Concerns, behavioral approaches and recommendations. Med Oral Patol Oral Cir Bucal 18(6): e862-e868.

15. Nagendra J, Jayachandra S (2012) Autism disorders: dental treatment considerations. J Int Dent Med Res 5(2): 118-121.

16. Jaber MA (2011) Dental caries experience, oral health status and treatment needs of dental patients with autism. J Appl Oral Sci 19(3): 212-217.

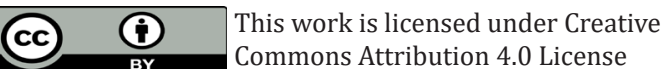

To Submit Your Article Click Here:

Submit Article

DOI: 10.32474/MADOHC.2018.03.000156

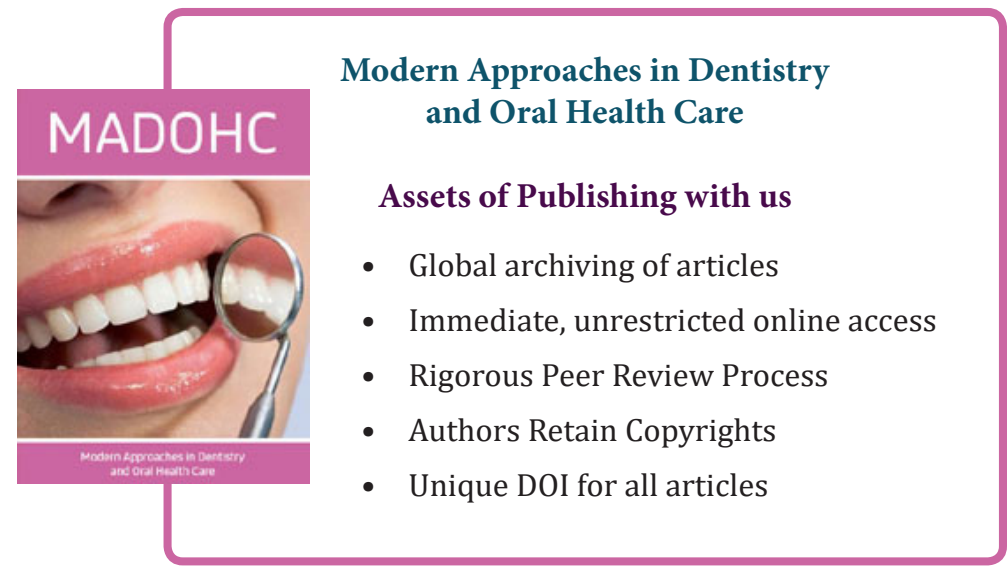

